\title{
Experimental Philosophy, Clinical Intentions, and Evaluative Judgment
}

\author{
LYNN A. JANSEN, JESSICA S. FOGEL, and MARK BRUBAKER
}

Recent empirical work on the concept of intentionality suggests that people's assessments of whether an action is intentional are subject to uncertainty. Some researchers have gone so far as to claim that different people employ different concepts of intentional action. ${ }^{1}$ These possibilities have motivated a good deal of work in the relatively new field of experimental philosophy. The findings from this empirical research may prove to be relevant to medical ethics. After all, the intentions of medical professionals are widely considered to be important in the ethical assessment of their actions. ${ }^{2}$ For example, in the debate over palliative sedation for terminally ill patients, it is often said that it is permissible for a clinician to administer a potentially lethal dose of pain medication to a patient, provided that he or she by doing so intends only to relieve the patient's suffering and does not intend to kill or hasten the death of the patient. This idea-that it can be permissible to bring about a foreseen but unintended effect (the patient's death), although it would not be permissible to intend to bring about this same effect-is central to the principle of double effect (PDE), which has found expression in both the law and the professional codes of medical organizations. ${ }^{3,4}$

Notwithstanding this point, over the past decade or so, a number of writers have challenged the value of focusing on the intentions of clinicians when considering questions of ethically permissible conduct. They have claimed that clinical intentions are often equivocal and multiple. ${ }^{5,6,7}$ They also have claimed that clinicians frequently have difficulty identifying what their intentions are in a given case. In light of the importance that intention plays in medical ethics, it is surprising that no research has been done to identify causes or psychological factors that might help to explain this uncertainty over intentions in clinical reasoning.

In this article, we address this issue head on. We first describe a study we conducted on intention ascription. Drawing on recent work in experimental philosophy, we investigated the possibility that the ascription of intentions to clinical actors in clinical settings is influenced by prior judgments about the goodness or badness of the consequences of the action in question. Our study was modeled on experimental studies in other contexts that have shown that people, when presented with a range of scenarios, are more likely to classify a side effect of an action as intended if the side effect is negative or reflects poorly on the actor than if it is positive or reflects well on the actor. $8,9,10,11$ We investigated whether this asymmetry in intention ascriptions was also present among physicians who were asked to ascribe intentions to clinical actors in certain well-defined clinical scenarios. After describing the study and its results, we discuss its implications for medical ethics. 


\section{Background}

A number of writers have suspected that the intentions of clinicians, particularly with regard to end-of-life care, are far from clear. ${ }^{12,13,14,15}$ Empirical research on this issue has tended to confirm this suspicion. For example, a recent study by Douglas et al. found that physicians in Australia had difficulty deciding whether a consequence of their interventions (the death of their patient) was an intended or unintended event. ${ }^{16}$ Virtually no empirical work has been done on the possible causes of the alleged uncertainty of these intention ascriptions. ${ }^{17}$ However, experimental philosophers have studied third-person intention ascriptions in detail outside the clinical context. This work has revealed surprising information about the commonsense or folk conception of intentional action. For example, through a series of experiments, Joshua Knobe demonstrated that people were much more likely to characterize a side effect of an action as intentional if they evaluated the side effect as harmful and less likely to do so than if they evaluated the side effect as helpful. ${ }^{18,19,20}$ The asymmetry in responses is puzzling, because the action that generates both the harmful and the helpful side effect is the same in both cases.

Knobe's experiment presented scenarios in which a company is planning to implement a program that will, as a side effect, either harm or help the environment. He found that respondents were more likely to characterize the side effect of the company's program as intended if they judged it to be harmful or morally bad and less likely to do so if they judged it to be beneficial or morally good. His hypothesis was that moral judgments condition intention ascriptions.

Following Knobe's lead, a common method of assessing intentionality among experimental philosophers has been to compare the responses of two groups to specific questions about the intent of an actor involved in a scenario involving either a harmful condition or a helpful condition. ${ }^{21}$ Using this method, researchers have consistently demonstrated the asymmetric responses described previously. ${ }^{22,23,24,25,26}$ Across a range of cases, subjects reliably indicate that side effects that were harmful were both intentional and blameworthy, whereas side effects that were helpful were reliably classified as not intentional and not praiseworthy. ${ }^{27}$ We used this same methodology to design cases stylized to the clinical context to help us achieve our study objectives.

\section{Method}

\section{Subjects}

Subjects consisted of 143 practicing physicians at a hospital located in the greater New York City metropolitan area. Institutional review board (IRB) approval was obtained from the host institution, and informed consent was obtained from all subjects who agreed to participate in the study. To be eligible to participate in this study, subjects were required to speak and read English and have a medical degree. Subjects ranged in age from 23 to 71 years, with a mean age of 33.8 years. Fifty of the subjects were women, and 90 of the subjects were men. Three subjects chose not to report their gender. The ethnic composition of the physician-subject population was $46.9 \%$ white, $8.4 \%$ Hispanic, 2.1\% African American, $0.7 \%$ black (not of U.S. origin), 27.3\% Asian or Pacific Islander, $2.8 \%$ mixed race, and $7.7 \%$ other. The religious composition of the physician-subjects was $10.5 \%$ agnostic, 
8.4\% atheist, 5.6\% Protestant, 23.8\% Catholic, 4.2\% Muslim, 20.3\% Jewish, and $22.4 \%$ other.

\section{Materials and Procedures}

Subjects were randomly assigned to one of two experimental groups (designated "Group A" and "Group B"). Sixty-eight subjects were randomly assigned to Group A, and 75 subjects were randomly assigned to Group B. Subjects in Group A were presented with two separate clinical scenarios depicting harmful patient outcomes following a physician intervention. Subjects in Group B were presented with the same two clinical scenarios; however, in these the physician intervention resulted in helpful rather than harmful outcomes. The four scenarios are described below.

1) Group A, Scenario 1 (harmful outcome): A patient was admitted to the city hospital with burns over 90 percent of his body following a house fire. On admission to the hospital, the patient was writhing in pain and was given the standard dose of pain medication. Later that day his treating doctor, Dr. Smith, told his colleague Dr. Jones: "The standard dose is not controlling the patient's pain. We need to increase his pain medication substantially (at least twice the dose the patient is already receiving)." Dr. Jones responded: "But increasing the dose of pain medication to that level could cause the patient to die."

Dr. Smith replied: "I don't care whether the patient lives or dies at this point. I just need to relieve his suffering. I am going to administer the pain medication."

Dr. Smith administered the pain medication, and, sure enough, just as Dr. Jones had worried, the patient died as a result of receiving it.

2) Group A, Scenario 2 (harmful outcome): Dr. Green is a cancer doctor operating a private practice. In recent years, insurance companies have decreased the amount of money they pay for the treatment of cancer patients, and this has caused Dr. Green's practice to experience severe financial difficulties. He has been eagerly seeking ways to improve his business's finances.

One day a representative from a major pharmaceutical company stopped by Dr. Green's office. The representative told Dr. Green of a promising new research study on breast cancer and offered Dr. Green a large sum of money if he helped to recruit and enroll eligible patients in the pharmaceutical company's research project. The representative told Dr. Green: "This deal will favorably improve your office's financial situation, but it also could expose the patients to risks of harm."

Dr. Green replied: "I don't care whether the patients are harmed by participating in the research. I just want to keep my business from going into bankruptcy. I am going to sign us up to do research with the pharmaceutical company."

Dr. Green agreed to participate in the pharmaceutical company's research project, and, sure enough, just as the representative warned, several of Dr. Green's patients were harmed as a result of participating in the research.

3) Group B, Scenario 1 (helpful outcome): A patient was admitted to the city hospital with burns over 90 percent of his body following a house fire. On admission to 
the hospital, the patient was writhing in pain and was given the standard dose of pain medication. Later that day his treating doctor, Dr. Smith, told his colleague Dr. Jones: "The standard dose is not controlling the patient's pain. We need to increase his pain medication substantially (at least twice the dose the patient is already receiving)." Dr. Jones responded: "That is a good idea, since increasing the dose of pain medication could also help the patient recover more quickly."

Dr. Smith replied: "I don't care whether the patient recovers quickly or not at this point. I just need to relieve his suffering. I am going to administer the pain medication."

Dr. Smith administered the pain medication and, sure enough, just as Dr. Jones had predicted, the patient's pain was managed, and this ultimately enabled the patient to recover more quickly.

4) Group B, Scenario 2 (helpful outcome): Dr. Green is a cancer doctor operating a private practice. In recent years, insurance companies have decreased the amount of money they pay for the treatment of cancer patients, and this has caused Dr. Green's practice to experience severe financial difficulties. He has been eagerly seeking ways to improve his business's finances.

One day a representative from a major pharmaceutical company stopped by Dr. Green's office. The representative told Dr. Green of a promising new research study on breast cancer and offered Dr. Green a large sum of money if he helped to recruit and enroll eligible patients in the pharmaceutical company's research project. The representative told Dr. Green: "This deal will favorably improve your office's financial situation, but it also could benefit the patients."

Dr. Green replied: "I don't care whether the patients are benefited by participating in the research. I just want to keep my business from going into bankruptcy. I am going to sign us up to do research with the pharmaceutical company."

Dr. Green agreed to participate in the pharmaceutical company's research project, and, sure enough, just as the representative had anticipated, some of the patients benefited as a result of participating in the research.

These scenarios were stylized to specific clinical situations that would be familiar to physicians. Importantly, the harm/help scenarios involving Dr. Smith were symmetrical, and the harm/help scenarios involving Dr. Green were symmetrical, but the scenarios involving Dr. Smith were not symmetrical with those involving Dr. Green. We predicted that physicians would judge Dr. Green's conduct less favorably than Dr. Smith's.

Following the reading of the clinical scenarios, physicians in both groups were asked to rate attribution of blame or praise for the clinical outcomes as well as attribution of physician intentionality. Blame and praise attributions were assessed on a scale from 1 to $6(1=$ no blame or no praise and $6=$ a lot of blame or a lot of praise). Intentionality ascriptions were assessed in a yes-no format. Subjects were also asked to briefly explain in writing their responses to the yes-no question about intentionality. After completing the questions relating to the two clinical scenarios, subjects were asked to complete a series of demographic questions. Age differences were assessed using $t$-tests. Differences in gender, ethnicity, and education level were assessed using a chi-square. 
Subjects were also invited to offer a justification for the intentionality ascriptions and praise or blame assessments that they provided. These qualitative reports were collected, reviewed, and coded by the research team. They were not used to alter the quantitative data reported subsequently.

\section{Results}

\section{Group A (Harmful Outcome)}

Scenario 1. In scenario 1, 85.3\% of the physicians stated that Dr. Smith did not intentionally cause the patient to die; $14.7 \%$ of the physicians stated that Dr. Smith did intentionally cause the patient to die. Physicians who did not think Dr. Smith intentionally caused the patient to die attributed less blame $(M=3.67$, $S D=1.68)$ than those who did think Dr. Smith intentionally caused the patient to die $(M=5.4, S D=.84)$. These differences were found to be significant $(t(66)=4.99$, $p=.002)$. No significant differences were found in response to the intentionality and blame questions based on any of the demographic variables studied.

Scenario 2. In scenario 2, 30.9\% of the physicians stated that Dr. Green did not intentionally harm the patients; $69.1 \%$ of the physicians stated that Dr. Green did intentionally harm the patients. Physicians who did not think Dr. Green intentionally harmed the patients attributed less blame $(M=5.05, S D=1.2)$ than those who did think Dr. Green intentionally harmed the patients $(M=5.79, S D=.46)$. These differences were found to be significant $(t(66)=2.73, p<.001)$. No significant differences were found in response to the intentionality and blame questions based on any of the demographic variables studied.

\section{Group B (Helpful Outcome)}

Scenario 1. In scenario 1, 64\% of the physicians stated that Dr. Smith did not intentionally help the patient recover more quickly; $36 \%$ of the physicians stated that Dr. Smith did help the patient recover more quickly. Physicians who did not think Dr. Smith intentionally helped the patient recover ascribed less praise $(M=3.17, S D=1.42)$ than those who did think Dr. Smith intentionally helped the patient recover $(M=4.31, S D=1.01)$. These differences were found to be significant $(t(71)=3.97, p=.001)$. No significant differences were found in response to the intentionality and blame questions based on any of the demographic variables studied.

Scenario 2. In scenario 2, 89.3\% of the physicians stated that Dr. Green did not intentionally benefit his patients by enrolling them in the research; $10.7 \%$ of the physicians stated that Dr. Green did intentionally benefit his patients by enrolling them in the research. Physicians who did not think Dr. Green intentionally benefited the patients ascribed less praise $(M=1.94 S D=1.17)$ than those participants who did think that Dr. Green intentionally benefited his patients $(M=3.38, S D=1.19)$. These differences were found to be significant $(t(73)=3.28$, $p=.002)$. No significant differences were found in response to the intentionality and blame questions based on any of the demographic variables studied. 


\section{Discussion}

The results confirm Knobe's asymmetry in the scenarios involving Dr. Green. A substantial majority of the respondents $(69.1 \%)$ characterized the harmful outcome as intended, whereas an even greater majority $(89.3 \%)$ characterized the helpful outcome as unintended. This difference in response is explained by the hypothesis that people are more likely to characterize an outcome of an action as intentional if they evaluate the outcome as harmful and less likely to do so if they evaluate the outcome as helpful. However, and interestingly, the same asymmetry in responses was not exhibited in the scenarios involving Dr. Smith. Respondents were inclined to characterize both the harmful and the helpful outcomes of Dr. Smith's actions as an unintended consequence of his intervention (85.3\% and $64 \%$, respectively).

The overall results from the scenarios involving Dr. Smith and Dr. Green provide insight into how physicians attribute intentions to actors in clinical settings. In three of the four scenarios, physicians consistently classified the side effects of the actions of the clinical actors as unintended consequences. However, in one scenario- the scenario involving a harmful outcome that results from the act of recruiting subjects into research-nearly 7 out of 10 respondents classified the side effect as intended. An explanation for this pattern of responses is that, in the scenarios involving Dr. Green, the respondents were more inclined to judge Dr. Green's conduct negatively. This evaluative judgment, in turn, conditioned their responses in ascribing intentions to him.

This explanation is strengthened by considering some of the differences between the scenarios involving Dr. Smith and Dr. Green. Dr. Smith is practicing medicine, whereas Dr. Green is engaged in pharmaceutical research. Respondents may have had a more favorable impression of the former activity than the latter. Similarly, Dr. Smith's conduct affects one patient, whereas Dr. Green's conduct affects a group of patients. This also might have led respondents to view Dr. Green's conduct in a less favorable light. A harsher evaluative judgment of Dr. Green as compared to Dr. Smith would explain why respondents were more inclined to characterize his harmful outcome as intentional.

The reported ascriptions of praise and blame provide further support for this explanation. Assignments of praise and blame typically reflect moral judgments, but it is also possible that they express nonmoral evaluative judgments. (Judgments of blame, for example, might have been informed by legal or professional standards that the respondents did not endorse on moral grounds.) Taken as a group, the respondents were more inclined to blame Dr. Green for his conduct in scenario 2 that resulted in a harmful outcome than they were inclined to blame Dr. Smith for his conduct in scenario 1 that resulted in a harmful outcome. This greater willingness to assign blame to Dr. Green compared to Dr. Smith for the harmful side effects of their actions may explain, in part, why respondents were more willing to characterize the harmful side effect of Dr. Green's actions as intentional compared to those of Dr. Smith. It is also possible that some of the respondents viewed Dr. Smith's actions in scenario 1 (harmful outcome) as justified, even though they had the negative side effect of the patient's death. After all, Dr. Smith's intervention in scenario 1 (harmful outcome) was motivated by the medically appropriate concern to alleviate the suffering of his patient. It is even possible that some respondents viewed the death of the patient in this scenario as a beneficial outcome, believing perhaps that continued suffering would have been 
worse than death. In the case of either of these possibilities, the more favorable judgment of Dr. Smith's conduct may have influenced respondents' ascription of intentions to him.

In light of these points, it might be questioned whether the "harmful" outcome in scenario 1 is properly characterized. Perhaps it is better viewed as neither harmful nor helpful. However, the fact that even those who viewed Dr. Smith's "harmful" outcome as unintended were, as a group, still inclined to assign some blame to him suggests that it is not inappropriate to characterize the outcome as harmful rather than helpful, even if some respondents believed that the harm was justified.

In contrast, respondents almost certainly viewed Dr. Green's actions in scenario 2 (harmful outcome) as unjustified. His actions were plainly medically inappropriate, and they were motivated by his own self-interested financial concerns. For this reason, the physicians who responded to the scenario involving Dr. Green may have been more inclined to characterize the harmful outcome of his actions as intentional. The fact that respondents, taken as a group, attributed more blame to Dr. Green than to Dr. Smith in the respective cases further supports this conjecture.

The results from the present study, in this way, provide support for the hypothesis that intention ascription in the clinical setting is influenced by prior evaluative judgments, at least when physicians are asked to ascribe intentions to third-party actors after they have been asked to ascribe blame or praise to the actions of these actors. This hypothesis is further substantiated by the narrative reports respondents provided in explanation of their answers to the quantitative questionnaires. As we have explained, respondents, by and large, assigned only a modest amount of blame to Dr. Smith for the death of the patient in scenario 1 (harmful outcome), and they generally classified the death of the patient as an unintended consequence of his actions. But those in the minority who classified the patient's death as an intended consequence of Dr. Smith's actions were much more inclined to blame him for his intervention. For example, several respondents who classified the death of the patient as an intended consequence of Dr. Smith's actions wrote that Dr. Smith should have been more careful than he was and that he should have explored other options. Likewise, with respect to Dr. Green's actions, the respondents who assigned a high amount of blame to him and classified the harmful outcome in scenario 2 as intentional faulted him for exposing his patients to harm. A number of respondents wrote that Dr. Green violated his duty to his patients and that "he sold himself out as a medical doctor." Other respondents stressed the suspect motives of Dr. Green's action. One respondent, for example, wrote, "He knew he would benefit at patient's expense. This tells me that the action is more intentional."

It is natural to wonder why the respondents did not take more seriously the statements of Dr. Smith and Dr. Green that they did not care about the potential side effects of their actions. If the respondents had done so, then would they not have classified the side effects in all four scenarios as unintended? The matter is more complex than it appears. Some writers have suggested that the concept of intentionality admits of multiple interpretations. ${ }^{28}$ On one interpretation, an actor intentionally brings about an effect of her action if she has foreknowledge that it will occur as a result of her action. On a second interpretation, an actor intentionally brings about an effect of her action only if the effect were part of her motive for acting. According to the first, but not the second, interpretation, a side effect that an actor did not care about could have been brought about 
intentionally. Thus it is possible that some of the respondents in our study made prior evaluative judgments about the conduct of the clinical actors in the scenarios presented to them and that these prior judgments, in turn, influenced the interpretation of the concept of intentionality on which they relied in their responses.

\section{Ethical Implications}

Conscientious ethical thinking about clinical practice calls on physicians to be able to classify the consequences of their clinical interventions as intentional or unintentional in a principled and consistent manner. This claim can be accepted by both proponents and critics of the PDE-because even if one rejects the PDE, one can acknowledge that intentions are ethically significant for clinical practice in other ways. The intentions behind clinical interventions affect how others view clinicians, and, more generally, they condition the meaning of these interventions. ${ }^{29,30}$ Even if a practicing clinician does not herself intend to bring about a particular outcome, if others ascribe to her an intention to do so, then her action will have a different meaning than it would have if they had not done so. ${ }^{31}$ Ethically conscientious clinicians thus must be aware not only of their own intentions in acting but also of how others are inclined to attribute intentions to them. Clinicians also have a duty to clarify their intentions when they are ambiguous, or at least to come to a better understanding of them. This seems especially true when the issues at stake are of great moral importance, such as the life-and-death issues that arise in the context of extraordinary palliative medicine.

Empirical study of the processes that influence the ascription of intentions to clinical actors may prove to be helpful in this regard. It may improve ethical judgments about clinical practice by making physicians more aware of the factors that condition the attribution of intentions both to themselves and to others. It is possible that the hypothesized mechanism at work in the present study-the claim that evaluative judgments condition the ascriptions of intentions to actorsdoes not apply to first-person intention ascriptions of practicing clinicians. Still, although this possibility is not ruled out by our research, it is noteworthy that our hypothesized mechanism would help to explain the uncertainty of clinical intentions reported in end-of-life cases. Because, as we have noted, uncertainty over clinical intentions in end-of-life cases is widely reported, we suspect that the mechanism identified in our study is at work in the first-person intention ascriptions of these clinicians. Further research would be necessary to substantiate this claim.

We believe that if prior evaluative judgments influence clinicians' judgments as to whether a side effect is properly characterized as intentional in both first-person and third-party cases, then our results could prove to be important for improving moral reflection on end-of-life care. On the assumption that the intentions of clinicians are relevant to the moral permissibility of a range of clinical interventions, clinicians need to come to a better understanding of the mechanisms that condition their ascription of intentions both to themselves and to others.

How, more precisely, might an improved understanding of the factors that influence one's ascription of intentions to oneself and others improve one's ethical judgments about clinical practice? Here is one illustration. Suppose that a physician believes that clinical intentions do make a contribution to the moral acceptability of a clinical intervention. That is, suppose that he thinks that the fact that a consequence of an intervention is unintended (or intended) is an independent factor that 
helps to determine the moral permissibility of the intervention. He might accept the PDE, for example. Now suppose that this physician learns that his practice of ascribing intentions, both to himself and to others, is itself determined by his prior judgments about the moral goodness of the intervention in question. This should give him pause. For now he will be in a position to know that the fact that a consequence of the intervention is unintended (or intended) is not an independent factor in determining its moral permissibility. It is, rather, a function of the judgment that the intervention is morally good or bad. Recognizing this should lead him to make revisions in his judgment. He might come to downplay the significance of his intentions, concluding that whether or not a consequence of an intervention is intended is not an independent factor in assessing the moral permissibility of the intervention. Alternatively, he might continue to believe that intentions are important to moral assessment but might make efforts to improve his practice of intention ascription so that he ascribes intentions in a more principled and consistent manner. Either way, he may be prompted to make changes in his moral judgments over all—changes that are designed to bring his moral judgments into coherent alignment with his practice of intention ascription.

\section{Conclusion}

The study of factors that influence the ascription of intentions, both to others and to oneself, has received virtually no attention in medical ethics. Many writers have simply taken the self-reporting of clinical intentions at face value. They have not sought to explain why intentions in the context of clinical medicine might be ambiguous or uncertain. Nor have they explored the possibility that clinicians might have a duty to come to a better understanding of their own intentions, particularly when they are making morally significant decisions. Building on methods employed in experimental philosophy, the present study provided evidence for the view that physicians' ascription of intentions to clinical actors is influenced by their prior evaluative judgment of the conduct in question. These findings could be important for improving the self-understanding of clinical decisionmaking. And, on the assumption that clinical intentions do make an ethical difference to clinical conduct, they ultimately could help to improve the ethics of clinical care.

\section{Notes}

1. Cushman F, Mele A. Intentional action: Two-and-a-half folk concepts? In: Knobe J, Nichols S, eds. Experimental Philosophy. New York: Oxford University Press; 2008:171-88.

2. Beauchamp TL, Childress JF. Principles of Biomedical Ethics. 4th ed. New York: Oxford University;1994, at 206-11.

3. Council on Ethical and Judicial Affairs. CEJA Report 5-A-08; 2008; available at http://ama. assn.org/amal/pub/upload/mm/369 (last accessed 7 Nov 2009).

4. Vacco v. Quill, 117 S. Ct. 2293 (U.S. 1997).

5. Quill TE. The ambiguity of clinical intentions. New England Journal of Medicine 1993;14:1039-40.

6. Quill TE. Principle of double effect and end-of-life pain management: Additional myths and a limited role. Journal Palliative Medicine 1998;4:333-6.

7. Douglas CD, Kerridge IH, Rainbird KJ, McPhee JR, Hancock L, Spigelman AD. The intention to hasten death: A survey of attitudes and practices of surgeons in Australia. Medical Journal of Australia 2001;175:511-51. 


\section{Experimental Philosophy, Clinical Intentions, and Evaluative Judgment}

8. Knobe J. Intentional action in folk psychology: An experimental investigation. Philosophical Quarterly 2003;16:309-24.

9. Knobe J. Intentional action and side-effects in ordinary language. Analysis 2003;63:190-3.

10. Nadelhoffer T. Bad acts, blameworthy agents, and intentional action: Some problems for juror impartiality. In: Knobe J, Nichols S, eds. Experimental Philosophy. New York: Oxford University Press; 2008, at 148 .

11. Mele AR. Intentional action: Controversies, data, and core hypothesis. Philosophical Psychology 2003;16:325-40.

12. See note 5, Quill 1993.

13. See note 6, Quill 1998.

14. See note 7, Douglas et al. 2001.

15. Douglas C, Kerridge I, Ankeny R. Managing intentions: The end-of-life administration of analgesics and sedatives and possibly slow euthanasia. Bioethics 2008;22(7):388-96.

16. See note 15, Douglas et al. 2008.

17. In a previous study, two of us asked first- and second-year medical students to attribute intentions to actors in well-defined clinical scenarios. See Jansen LA, Fogel JS. Ascribing intentions in clinical decision-making. Journal of Medical Ethics 2010 Jan:2-6. This study provided preliminary evidence for the view that the ascription of intentions to clinical actors is strongly influenced by prior evaluative judgments. But this study, suggestive as it was, did not rule out the possibility that the intention ascriptions of practicing clinicians differ significantly from those of relatively inexperienced medical students.

18. See note 8 , Knobe 2003.

19. See note 9, Knobe 2003.

20. Knobe J. The concept of intentional action: A case study in the uses of folk psychology. Philosophical Studies 2006;130:203-31.

21. See note 8, Knobe 2003.

22. See note 8, Knobe 2003.

23. Knobe J, Nichols S, eds. Experimental Philosophy. New York: Oxford University Press; 2008, at 148.

24. See note 11, Mele 2003.

25. See note 17, Jansen, Fogel 2010.

26. Lagnado DA, Channon S. Judgments of cause and blame: The effects of intentionality and foreseeability. Cognition 2008;108:754-70.

27. Knobe's research has attracted its share of critics. Some have claimed that there are special features of intentional action that explain the asymmetric responses. For a response to the critics, and an updated discussion of the issue, see Pettit D, Knobe J. The pervasive impact of moral judgment. Mind and Language 2009;24(5):586-604.

28. Nichols S, Ulatowski J. Intuitions and individual differences: The Knobe effect revisited. Mind and Language 2007;22(4):346-65.

29. Scanlon TM. Moral Dimensions. Cambridge, MA: Harvard University Press; 2008.

30. Jansen LA. Disambiguating clinical intentions: The ethics of palliative sedation. Journal of Medicine and Philosophy 2010 Jan:1-13.

31. See note 29 , Scanlon 2008 